\title{
A Novel Periodic CPW UWB Low Pass Filter With Large Rejected Band
}

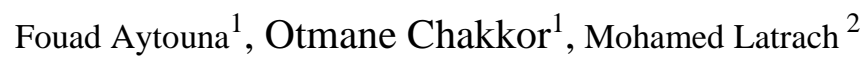 \\ ${ }^{1}$ ENSA, Abdelmalek Essaadi, University, Tetouan, 93000, Morocco \\ ${ }^{2}$ RF\& Microwave Group, ESEO, Angers, France
}

\begin{abstract}
In this paper, we present a new UWB CPW low pass filter structure by using periodic elements. The originality of this work is to develop a neFigure 4 showsw UWB LPF structure which is compact, miniature, and easy for fabrication. The validated LPF is a compact planar filter easy to associate with others microwave planar circuits, having a large band pass and a large rejection band. The final circuit is simulated and optimized by using the electromagnetic solver ADS (Advanced Design System). After many series of optimizations, we have validated the final circuit into simulation by using different optimization methods taking into account a high density of meshing in order to cover the whole circuit. The simulated LPF circuit shows good results in term of matching input impedance and insertion loss with a cut-off frequency of $6.5 \mathrm{GHz}$. The entire area of the proposed LPF is $16 \times 40 \mathrm{~mm}^{2}$.
\end{abstract}

.Keywords: CPW, UWB, LPF, Periodic Structure.

\section{Introduction}

Periodic structures of different types have always been a field of interest for researchers. They are actually used in many applications in the microwave and millimeter-wave regime [1]. The periodic structures have been used to fabricate high-performance filters, to perform harmonic tuning in power amplifiers, to suppress superior's harmonic and to enlarge the band pass [2-5]. Coplanar Waveguide (CPW) structures are one of the important subjects for the miniaturization of microwave integrated circuits (MICs). Due to uniplanar structure, low dispersion effect and simple fabrication process, CPW are used more than microstrip structures in the planar technology filter applications [6]. Harmonic-suppressed and wide stop-band properties have been highly demanded in millimeter systems to reject the spurious responses caused by nonlinear devices, such as high power amplifiers, mixers, and oscillators, etc Different approaches can be used to reach this goal like employing a periodic structure [7-8] or a Defected Ground Structure (DGS) [9], many research activities have been performed in order to apply it to microwave LPF circuits [10].

Many techniques can be used to implement such filters like stepped-impedance, coupled line, using coupled resonators, periodic structures and others. In order to design a planar filter many steps can be followed. Firstly, we can start by designing a low pass filter prototype using Butterworth, Chebyshev approximations [11]. The prototype g-values are scaled (demoralized) to the desire filter termination resistance and cut-off frequency as follow:

$$
\mathrm{L}=\frac{\mathrm{gR}}{\omega}
$$




$$
\mathrm{C}=\frac{\mathrm{g}}{\omega \mathrm{R}^{\prime}}
$$

High pass, band pass and stop-band can be obtained by applying an L-C transformation on low pass filter [12].

The next step is use the Richards' transformation, which allows the inductors and capacitors of a lumped-element filter to be replaced with short-circuited and open-circuited transmission line stubs as depicted in Figure 1.
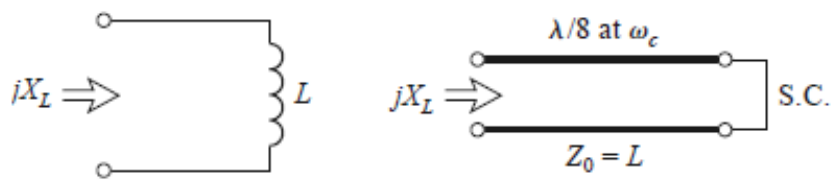

(a)
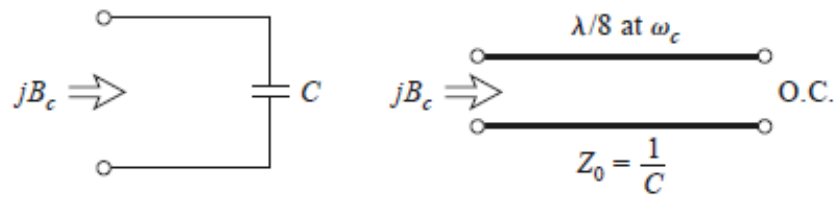

(b)

Fig.1. Richards' transformation. (a) For an inductor to a short-circuited stub. (b) For a capacitor to an open-circuited stub.

The transformation

$$
\Omega=\tan \beta l=\tan \frac{\omega l}{\vartheta_{\mathrm{p}}}
$$

Map $\omega$ plane to $\Omega$ plane. if we replace the frequency variable with $\omega$, we can write the reactance of an inductor as:

$$
\begin{array}{r}
\mathrm{jX}_{\mathrm{L}}=\mathrm{j} \Omega \mathrm{L}=\mathrm{jL} \tan \beta \mathrm{l} \\
\mathrm{jB}_{\mathrm{c}}=\mathrm{j} \Omega \mathrm{C}=\mathrm{j} C \tan \beta \mathrm{l}
\end{array}
$$

In addition to these, kuroda identities can be very useful in making the implementation of Richard's transformations more practicable. We can use Kuroda's Identities [13] to:

- Physically separate transmission line stubs.

- Transform series stubs into shunt stubs.

- Change impractical characteristic impedances into more realizable ones.

In general, the filter synthesis isn't always possible; therefore we can achieve new filter structures by using optimization methods. In this paper, we have used the optimization methods to achieve a novel LPF based on the coplanar waveguide (CPW) with improving the insertion loss and stop-band performances. 


\section{Design procedure}

To develop this novel structure, we have done a bibliography study, in order to have an idea about the different shapes and techniques used for such design. By consequent, we have started our work taking into account the study done in [14]. The filter design is started by passing from a simple CPW line, in which we have inserted octagonal shape as shown in Figure 2.



Fig.2. The geometry of the CPW (Ws $=16 \mathrm{~mm}, \mathrm{Ls}=14 \mathrm{~mm}, \mathrm{~s}=0.5 \mathrm{~mm}$ et $\mathrm{W}=2 \mathrm{~mm})$. The simulation results of this filter structure are depicted in Figure 3.

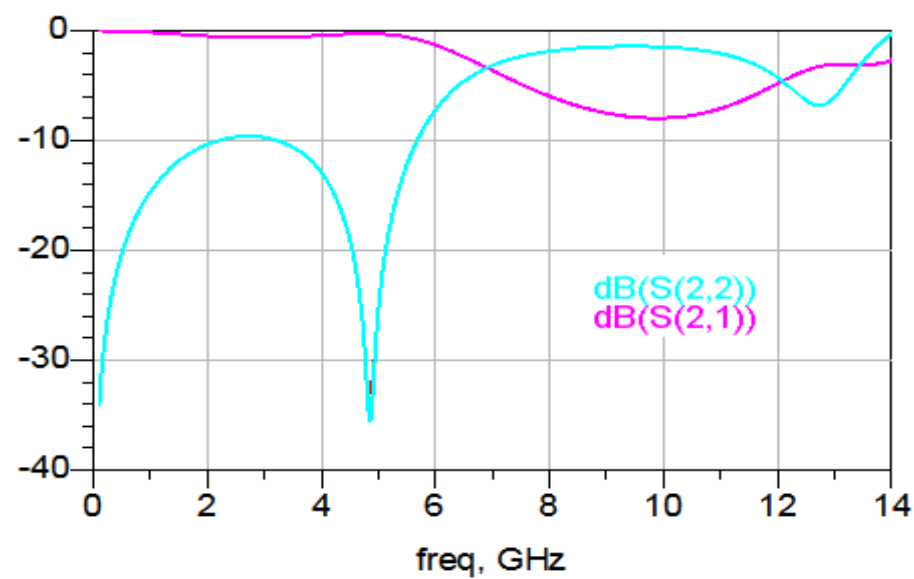

Fig.3. The S-parameters of the simulated CPW line versus frequency.

The Figure 3 shows the simulation results of the structure with one cell, as we can conclude, we have obtained a low pass filter behavior with a cutoff frequency equal to $6.77 \mathrm{GHz}$ correspending to a reflection coeffecient around $-10 \mathrm{~dB}$ in the whole bandwidth with an insertion loss less than $-0.5 \mathrm{~dB}$. In order to enhance the rejection band characteristics we have done another study based on the technique of the use of the periodic structure. The number of unit cell and the distance between cells influence the rejection band characteristics (Aytouna et al., 2015). 
After many series of simulation using optimization methods integrated in ADS, we have validated into simulation the proposed CPW LPF presented in Figure 4. The final proposed CPW LPF structure contains 4 cells which gave the good performances.

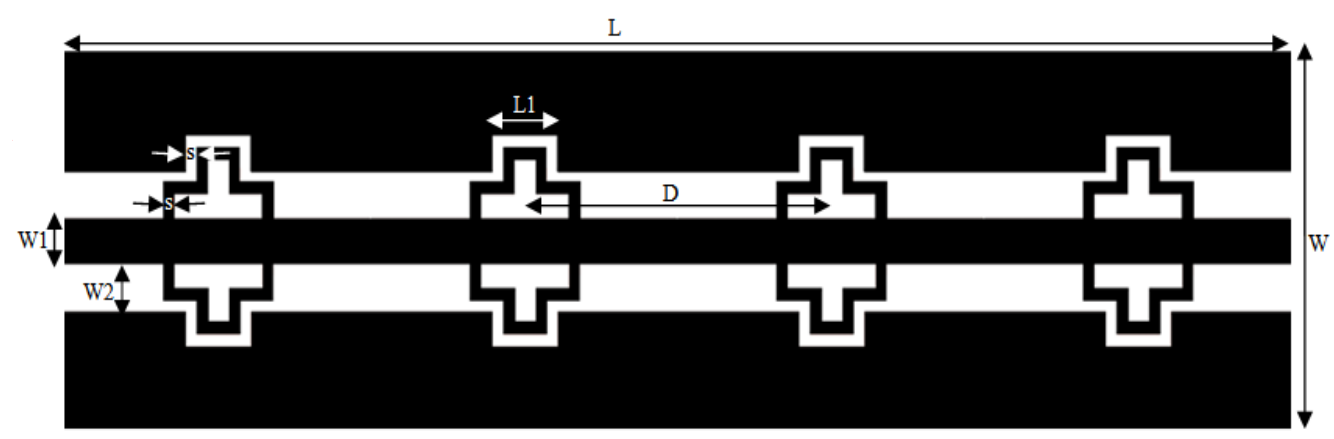

Fig.4. The topology of the proposed LPF.

The optimized parameters are presented in Table $\mathbf{1 .}$

Table 1. Dimensions of the proposed CPW LPF structure.

\begin{tabular}{cc}
\hline Parameters & Values $(\mathbf{m m})$ \\
\hline W & 16 \\
W1 & 2 \\
W2 & 2 \\
L & 40 \\
L1 & 3 \\
D & 9 \\
S & 0.5 \\
\hline
\end{tabular}

This CPW LPF is printed on an FR4 substrate with a thickness of $1.6 \mathrm{~mm}$, a dielectric permittivity $\varepsilon_{\mathrm{r}}=4.4$ and loss tangent $\tan \delta=0.025$.

Figure 5 illustrates the $S$ parameters of the proposed filter. 


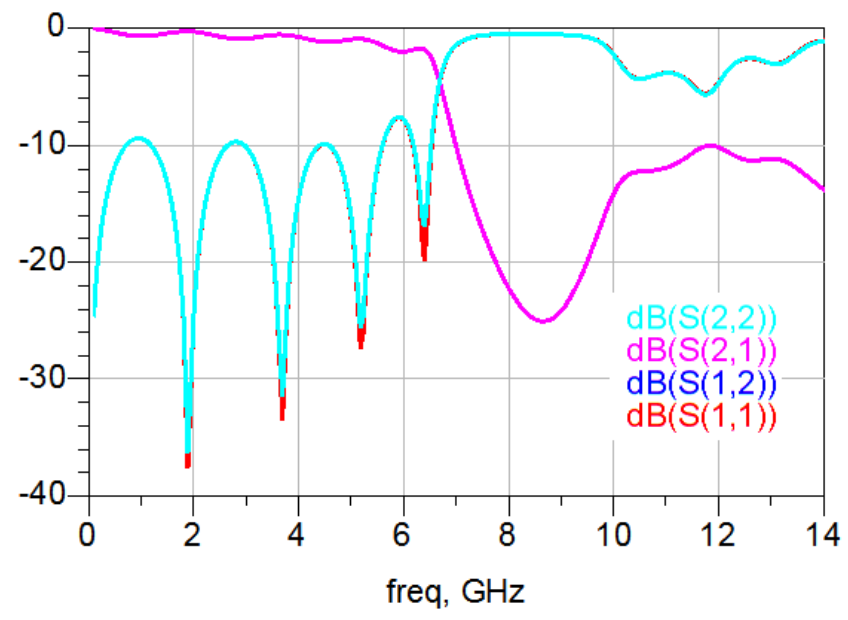

Fig.5. S-parameters versus frequency of the designed CPW LPF

As depicted in Figure 5 we have obtained good results in term of insertion loss around $0.8 \mathrm{~dB}$, a cutoff frequency of $6.77 \mathrm{GHz}$ and a good rejection until $15 \mathrm{GHz}$. These results are due to the insertion of periodic structures.

To show the effect of the variation of the distance and the number of cells, we have conducted a series of simulations based on two parameters:

\subsection{Effect of the number of cells}

The first study is done by fixing the distance between cells at $9 \mathrm{~mm}$. Figure 6 and Figure 7 illustrate the S-parameters versus frequency of the designed LPF by changing the number of cells.

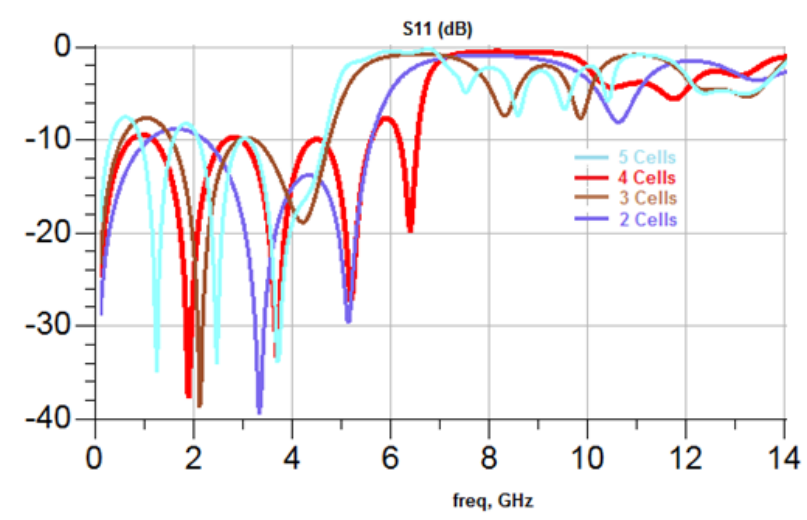

Fig.6. S11 parameter versus frequency for different number of cells of the proposed LPF. 


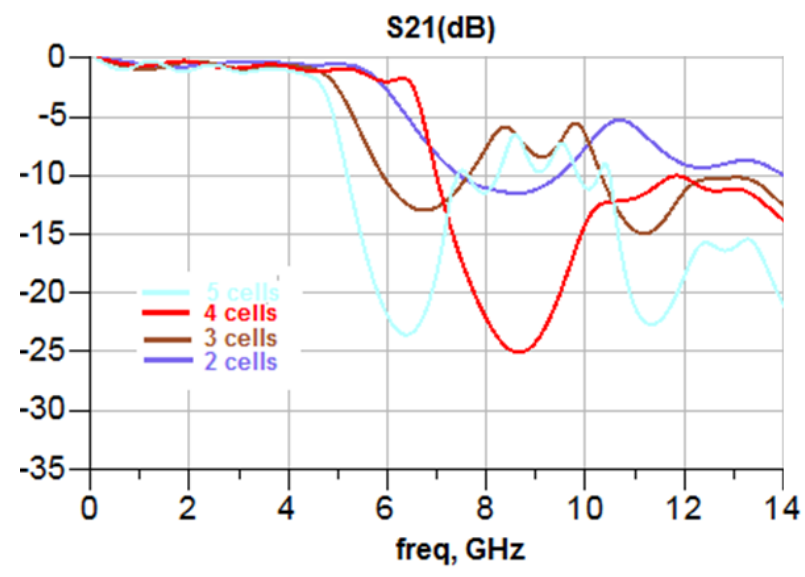

Fig.7. S21 parameter versus frequency for different number of cells of the proposed LPF.

As shown in Figure 6 and Figure 7 the use of adequate number of cells in the proposed CPW LPF permits to enlarge the rejection band.

\subsection{Effect of the distance between cells D}

The second study is done by fixing the number of cells; in this case we have used 4 cells and we have changed the distance D between cells, the different results obtained are presented in Figure 8 and Figure 9.

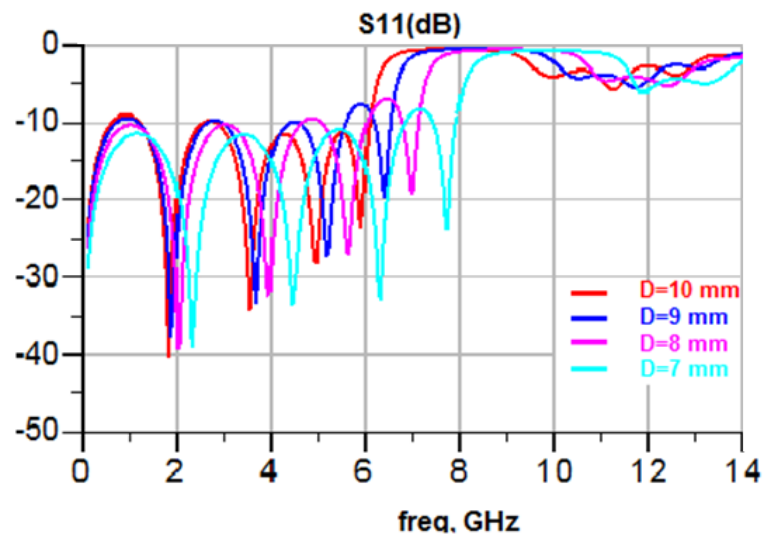

Fig.8. S11 versus frequency for different value of distance between cells of the proposed LPF. 


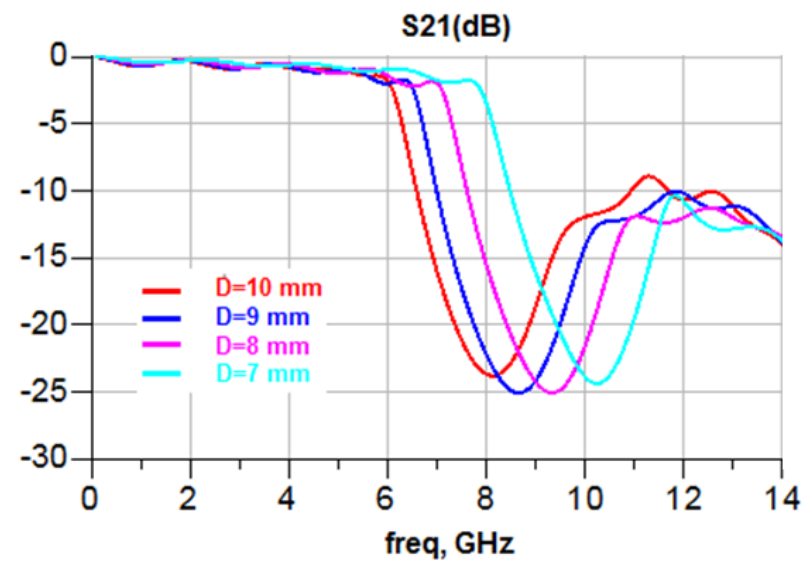

Fig. 9. S21 versus frequency for different distance between cells of the proposed LPF

To show the flow of energy in the band pass and rejected band, we have launched a simulation which confirms the function of the CPW LPF filter. Figure 10 presents surface current distribution, one in the bandwidth at $2.58 \mathrm{GHz}$ and another one at $10 \mathrm{GHz}$ in the rejected band which validate the frequency bands of the proposed filter.

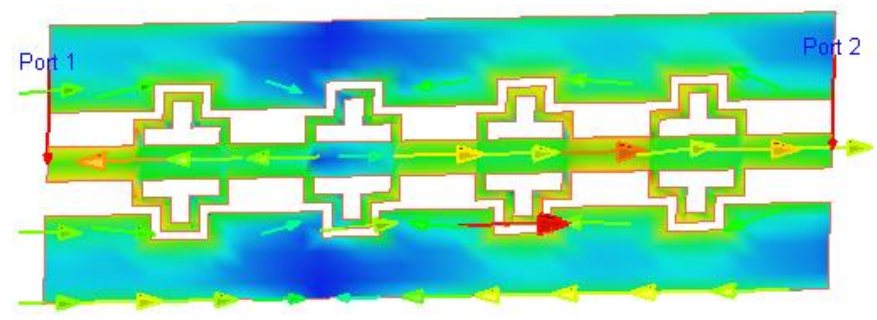

(a) at $2.58 \mathrm{GHz}$

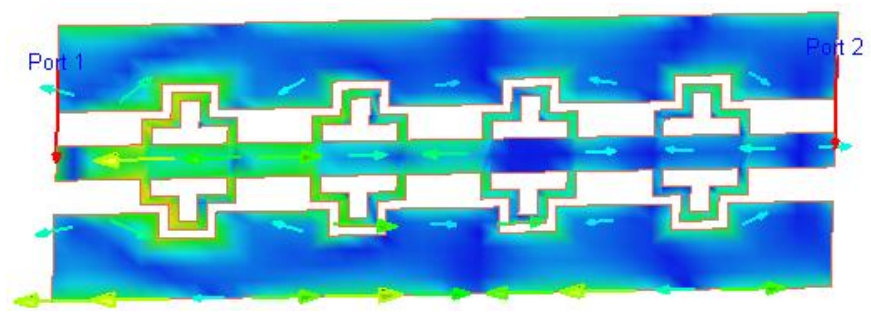

(b) at $10 \mathrm{GHz}$

Fig.10. Presents the current distribution at $2.58 \mathrm{GHz}$ and at $10 \mathrm{GHz}$ 


\section{Conclusion}

This work comes with a new configuration of LPF structure based on the use of CPW technology and periodic structures formed by octagonal shape slots permitting to adjust the bandwidth and to enlarge the rejection band. The design procedures were based on many optimization methods integrated into ADS. The simulation of the LPF was done taking into account a high mesh density to cover the whole circuit. The final proposed filter structure can be used for wireless communications and many other microwave applications. The methodology followed in this study can be used to match the LPF filter to another frequency band.

\section{Acknowledgement}

We have to thank Pr. M. Latrach and his research Team RF\& Microwave in ESEO Engineering institute in Angers in France for all the support brought to our research studies by permitting us to use Electromagnetic solvers and instruments of test.

\section{References}

[1] Yablonovitch, E.: Photonic band-gap structures. J. Optical Soc. America B. pp. 283-295 (1993)

[2] Yang, F. R., Coccioli, R., Qian, Y. Itoh, T.: Analysis and application of coupled microstrips on periodically patterned ground plane. IEEE MTT-S Int. Microwave Symp. Dig. pp. 1529-1532 (2000)

[3] Hang, Radisic, V., Qian, Y.,Itoh, T.: High efficiency power amplifier with novel PBG ground plane for harmonic tuning. IEEE MTT-S Int. Microwave Symp. Dig. pp. 807-810 (1999)

[4] Yang, F. R., Ma, K. P., Qian, Y., Itoh, T.:A novel TEM waveguide using compact photonic-bandgap (UC-PBG) structure. IEEE Trans. Microwave Theory Tech. pp. 2092-2098 (1999)

[5] Ma, K. P., Kim, J., Yang, F. R., Qian, Y. Itoh, T. :Leakage suppression in stripline circuits using a 2-Dphotonic bandgap lattice. IEEE MTT-S Int.Microwave Symp. Dig. pp. 73-76 ( 1999)

[6] Meng, Q., Zhang, Pu, X., J., 2009. :A Novel CPW Low-Pass Filter Using Electromagnetic Bandgap Structure. In: Proc. IEEE. Int. Conf. Appl. Supercond. Electromagn. Devices. pp. 267-269 (2009)

[7] Yang, F.-R., Qian, Y., Itoh, T.: A novel uniplanar compact PBG structure for filter and mixer applications. IEEE MTT-S Int. Dig. pp. 919-922 (1999)

[8] Aytouna, F., Zbitou, J., Aghoutane, M. , Touhami, N.A. , Tribak, Latrach, A. M.:A Novel CPW BandPass Filter Integrating Periodic Rectangular Slot Cells. Journal of Engineering Science and Technology Review. pp. 131-134 (2015)

[9] Ahn, D., Park, J.-S., Kim, C.-S., Kim, Qian, J., Y., Itoh, T.: A design of the low-pass filter using the novel microstrip defected ground structure. IEEE Trans. Microw. Theory Tech.pp.86-93 (2001)

[10] Chen, H.-J., Huang, T.-H., Chang, C.-S., Chen, L.-S., Wang, N.-F., Wang, Y. [10] H., Houng, M.P.:A novel cross-shaped DGS applied to design ultra-wide stopband low-pass filters. IEEE Microw. Wireless Compon. Lett. pp. 252-254 (2006)

[11] Hettak, K., Delisle, G., 1989. :A new miniature uniplanar lowpass filter using series resonators. IEEE MTT-S. pp. 1193-1196 (1989)

[12] Ishii, T. K.: Hand book of Microwave Technology, components and devices. by academic press, Inc., USA (1995)

[13] Pozar, D. M.: Microwave Engineering. John Wiley\& Sons, Inc., USA (2012)

[14] Sor, J., Qian, Y.: Miniature low-loss CPW periodic structures for filter applications. IEEE Transactions on Microwave Theory and Techniques .pp. 2336-2341 (2001) 